\title{
1. Energy capture and modernity
}

Our ability to capture vast amounts of energy and use it well is - in the sweep of human history - relatively recent (Cook, 1971). This capability has transformed living standards and productivity at work beyond all conceivable imagination just 250 years ago. Before then, and from at least the emergence of human language and culture about 70,000 years ago, human material existence changed comparatively little. The agricultural revolution changed the way humans obtained food and organized societies, but this revolution barely raised living standards over more than ten millennia, at least in a sustained way. In contrast, the impacts of two industrial revolutions - the first fuelled by coal and the second by oil and electricity—over two centuries were revolutionary. They transformed societies and lifted living standards to unprecedented heights. While there were important societal and political underpinnings to the industrial revolutions, they were enabled from an energy and technology perspective by accumulating scientific knowledge and its engineering application - an industrial enlightenment (Mokyr, 2002, p. 35). With these innovations, buildings became better built and more comfortable, well-lit and productive places to live and work. Road and sea transport became faster, safer and more affordable, and rail and air transport possible. Productivity-enhancing equipment and appliances spread through factories, offices and households. In modern societies, fossil fuels do much of the work.

This transformation to modern societies, however, is having profound impacts on the Earth - its oceans, surface and atmosphere - as human capabilities flourish and populations grow. Economic development is largely a response to pressing physical and material needs, which have been understandably in sharp relief. Wider impacts on the environment typically have been neglected until course corrections were compelled, such as the gradual deforestation of Britain for agricultural land, building materials and fuel over centuries, and eventual recourse to coal (R.C. Allen, 2009, pp. 84-90). But it is the current use of fossil fuels that is associated with poor local air quality, especially in urban areas, and with increasing the risks of climate change due to rising concentrations of carbon dioxide and other greenhouse gases in the Earth's atmosphere (IEA, 2016; IPCC, 2018).

The contexts for transforming current energy systems are complex, however. Some relate to the social, political and economic contexts for change, of which the interplay between two industrial revolutions and societal transformations 
provides powerful historical illustrations. The industrial enlightenment and technological innovations it spawned underpinned the first sustained rise in living standards, a development pathway initiated in a few countries and soon followed in many others. Over time, successive waves of technological innovation accelerated economic growth, industrialization and urbanization. These economic and societal transformations were also associated with profound political changes, including the emergence of modern nation states. In modern societies, economies and energy systems are now deeply interdependent. Almost all firms and households in advanced industrialized countries and many in developing ones depend on modern energy supplies for their economic and household activities. ${ }^{1}$ Thus, to transform current energy systems, most firms and households must change to low-carbon energy and technologies. But such changes raise challenging economic, social and political issues. They include vast scales of change in terms of the number and value of investment decisions, 'lock-in' of some incumbent technologies in investment decisions of individual firms and households, and distributional impacts within and across societies.

Other critical aspects to transforming energy arise from its country, sectoral and temporal dimensions. Again, the two industrial revolutions along with more recent energy-related innovations provide useful examples. Technological innovations that eventually proved commercially successful tended to emerge initially in those countries with capacity for innovation and economic specializations in primary industries and, over time, manufacturing. The pace of sectoral change in these initial markets tended to be slow, as the technologies and products were refined and adapted to specific uses. However, in subsequent markets, the pace of sectoral change accelerated, benefiting from experiences gained in initial markets and earlier innovations. Government interventions also accelerated some innovations and commercialization of energy-related technologies in the twentieth century. Similar country, sectoral and temporal variations are seen in current changes to low-carbon technologies, including the characteristics of incumbent technologies and their low-carbon alternatives. But before describing the historical backdrop to transforming current energy systems and assessing the temporal and spatial dimensions of change, it is useful to explain what energy is.

\section{ENERGY}

Energy is everywhere. The Sun showers the Earth's surface in two hours with more electromagnetic energy than all the primary energy humans capture in a year (Tsao et al., 2006). Solar irradiance and the Earth's gravity drive the water cycle-evaporation, cloud formation, precipitation and flowing water in streams and rivers. Differences in the Earth's surface temperatures, particu- 
larly between large areas of land and water, cause winds and ocean waves as its gravity is sufficiently forceful to retain an atmosphere. The Moon's gravity and its orbit around the Earth cause tides to ebb and flow. There is also the Earth's internal heat, which comes from radioactive decay of uranium and other isotopes in its crust and mantle as well as heat from its formation and molten metal inner core (Davies and Davies, 2010). However, the Sun is the dominant source of energy at the Earth's surface (more than 99 per cent).

Most life on Earth obtains its energy directly or indirectly from the Sun, although only a small fraction of solar irradiance is absorbed in this way and converted annually into chemical energy stores such as biomass $(0.1$ per cent; Barber, 2009). Plants on land and phytoplankton at sea use sunlight to convert elements - mostly nitrogen, phosphorous and potassium from soils and carbon, hydrogen and oxygen from air and water-into new biomass. Crop plants and some algae are relatively efficient at this photosynthesis process, converting 1-3 per cent of the sunlight that reaches these plants or organisms into energy stores (Blankenship et al., 2011). Animals digest plants or other animals to obtain energy in chemical form, mostly carbohydrates, fats and proteins. Fossil fuels are energy stores from fossilized remains of ancient plants and phytoplankton exposed to heat and pressure within the Earth's crust over millions of years.

Energy is also everything. Mass and energy are related, with a small amount of mass equivalent to a vast amount of energy. The energy of matter with mass is proportionate to its mass times the speed of light squared (Einstein, 1905; Rainville et al., 2005). Nuclear reactions are examples of this relationship working in one direction. Within the Sun, the fusion of hydrogen nuclei into lighter helium nuclei releases a vast amount of electromagnetic energy. On a very much smaller scale, fission within a nuclear power plant reactor splits apart the nuclei of uranium isotopes, reducing their mass slightly and yielding a substantial amount of energy.

While energy is everywhere and everything, it is hard to pin down precisely what it is. Energy takes many forms - electromagnetic (ultraviolet radiation, visible light and infrared radiation), chemical (food, feed and fuels), thermal (heat), kinetic (motion), electrical, nuclear and gravitational. There are many natural and man-made processes for converting one form of energy to another. For example, humans and other animals convert food and feed into life and motion. Burning biomass, like wood, converts fuel into heat. The internal combustion engine converts heat from burning liquid fossil fuels into motion. A nuclear power plant converts fissile material into electricity through, first, its conversion into heat and then motion. A working definition of energy is the property of transforming matter that has capacity to perform work, such as causing heat, light, motion and interaction of molecules, including life on Earth. $^{2}$ 
One unit of measure for energy, a joule $(\mathrm{J})$, is defined by an amount of work, specifically the amount of force required to accelerate a kilogram of mass by one second per metre over the length of a full metre. ${ }^{3}$ Power is the flow of energy over time and is measured in joules per second or Watts (W). Another useful measure of energy is a Calorie (large calorie or kcal), which is the amount of heat required to raise the temperature of one kilogram of water (at sea level) by one degree Celsius (C), which is a measure of heat intensity (temperature). To give a sense of scale, moderately active adult females and males requires $2400 \mathrm{kcal}$ and $2800 \mathrm{kcal}$ per day, respectively, which is equivalent to 10 million $\mathrm{J}$ (or 10 megajoules (MJ)) and $11 \mathrm{MJ}$ per day (FAO, 2004, pp. 35-52). The world average per capita daily dietary energy supply from food is about 2900 calories or $12 \mathrm{MJ}$ per day. ${ }^{4}$ This daily amount totals to just over four gigajoules (GJ) per year. In comparison, current average annual per capita final energy use in advanced industrialized and developing countries, excluding food, is about $110 \mathrm{GJ}$ and $35 \mathrm{GJ}$, respectively. ${ }^{5}$

\section{ENERGY AND SOCIETAL TRANSFORMATIONS}

Brief narratives of the agricultural revolution and two industrial revolutions highlight the contexts for historic energy-related innovations and their impacts on economic activity and living standards, organization of societies and development of political order. They draw out both positive and negative aspects of change, and point to factors assessed to have contributed to both material and societal transformations at key historical junctures. The back story to the underpinning technological changes, which span 12,000 years, is much human trial and error with countless more and mostly untold failures than successes, which is likely why the timespan to reach modernity is so long.

\section{The Agriculture Revolution and Settlement}

While humans foraged for food and gathered wood and other biomass for fuel for most of their history, about 12,000 years ago - as the last glaciation ended and the climate warmed naturally-humans began to engage in agriculture and live in settlements. ${ }^{6}$ Archaeological evidence has unearthed remains of early human settlements in an arc of rolling hills curving around the Tigris and Euphrates rivers in the Middle East as well as the Indus River and Huang He (Yellow River) valleys in Asia. While the transition from hunting and gathering to agriculture and settlement is not well understood, fixed dwellings were likely enabled by domestication of wild grasses and other plants with seeds rich in carbohydrates and some proteins - barley, lentils and wheat in the Middle East and millet and rice in Asia. Domestication of animals for food- 
initially sheep and subsequently cattle and pigs in the Middle East-added regular sources of proteins and fats to diets.

Settled communities, however, co-existed alongside hunting and gathering tribes for millennia. This observation suggests that benefits (controllable food supplies) and costs (risks of disease and predation) in making the transition to settlements were finely balanced. They only tilted towards settlement where conditions were favourable and because of higher human fertility rates in settlements (Scott, 2017, pp. 87-92 and 113-5). Over time, human agriculture and settlements spread across the world as agricultural capabilities developed and adapted to local environments. For example, settlements in what is today Mexico were associated with domestication of corn and potatoes in Bolivia and Peru.

Subsequent energy-related technological changes took the form of domestication of animals for work - water buffalo in Asia around 6000 years ago; asses, oxen and camels in the Middle East 5000 years ago; and horses in Asia and the Middle East around 4000 years ago. Development of tools such as wooden seed drills, leather harnesses for draught animals and wooden ploughs to till soils enabled an intensification of agriculture to feed both domesticated animals and larger populations. Human capabilities and technologies continued to expand gradually. Progress took many forms - irrigation canals and fertilizer from organic wastes, crop rotations, wooden wheeled carts, pottery and bricks fired in kilns and charcoal and smelting of metal ores. The first major renewable energy technologies beyond biomass and draught animals appeared in the Asia and the Middle East around 2000 to 1500 years ago: ships capable of sailing into the wind, and windmills. By 1000 years ago, these renewable technologies along with water wheels were widely used in Asia, Europe and the Middle East.

Human material progress over millennia, though, was largely matched by expanding populations and average living standards barely rose in a sustained way over time. For example, by $1700 \mathrm{CE}$ (all dates in Common Era), before industrialization began in earnest, Holland and England, then among the richest nations in the world, had estimated real per capita income levels of about $\$ 1,920$ and $\$ 1,660$ (all real incomes are in 2011 International $\$$ ), equivalent to around $\$ 5$ per day. ${ }^{7}$ Their annual growth rates over the preceding five centuries averaged about 0.1 per cent, albeit interspersed with many growth episodes and reversals (Fouquet and Broadberry, 2015). By 1700, estimated per capita income in India reached \$1,200, Germany \$910 and Japan \$840. To give a sense of scale, the monetary equivalent of a subsistence income level, including the value of informal activities such as subsistence farming, is about $\$ 700$, equivalent to $\$ 1.90$ per day (Bolt et al., 2018).

In 1700, average per capita energy use in Holland and England, which were still largely agricultural societies, was in the range $25 \mathrm{GJ}$ to $30 \mathrm{GJ}$ per year 
(Malanima, 2006; Warde, 2007, pp. 131-8). This energy was largely garnered through food and feed, draught animals, wood for fuel and other rudimentary renewables. They included watermills and windmills for processing food, making textiles and crushing metal ores; charcoal for smelting metal ores; and sailing ships for transport. England also used some coal for heating dwellings.

From the agricultural revolution to the first industrial revolution, sustained gains in living standards were glacial and subject to Malthusian pressures (Galor, 2005). However, intensification of agriculture, growing yet vulnerable settlements and development of trade contributed to the development of much more complex societies. They included not only settlements but also early state formation with some central authority that raised resources and organized capacity for human coercion and warfare (Carneiro, 1970; Fukuyama, 2011, pp. 458-83, Scott, 2017, pp. 128-39). These political developments involved taxation of agricultural production, conquest of others' settlements and slavery, with theft and human exploitation garnering greater prosperity for some at the expense of many others during the Malthusian epoch.

\section{The First Industrial Revolution: Coal, Steam and Modern Nation States}

The epochal transition to modern fossil fuels from traditional biomass and rudimentary renewables began as forests became depleted from intensive use of wood for fuel and building material and land clearance for agriculture. ${ }^{8}$ Initially, coal was used simply as a substitute for wood as a fuel for heat. This substitution first took place at scale in England as forests became more distant from cities, with a growing population, mounting pressures on land use from agriculture and deforestation. Also, coal seams were visible at the surface and close to the sea, and thus low-cost to mine and transport by ship. The transition to coal gathered pace in the eighteenth century with the invention and refinement in England of the steam engine, an innovation that emerged amidst a growing culture of scientific investigation and its mechanical applications as well as the increasing diffusion of knowledge through society (Mokyr, 2002, pp. 56-76; Jacob, 2014, pp. 20-31). The engine's capacity to do work offered a substitute to draught animals and workers as their costs and wages began to rise and the costs of energy services from coal and steam technologies declined (R.C. Allen, 2009, pp. 138-44; Jacob, 2014, pp. 66-82). This was the first machine to convert heat in the form of steam from burning fuel into useful motion. It worked by expanding steam from a boiler into a cylinder to drive a reciprocating piston, and its first use was to pump water from coal mines to boost production. Coal and coke were also increasingly used in smelting metal ores as a substitute for wood and charcoal as forests became depleted and wood relatively expensive. 
As their designs became more efficient through experience-based learning, steam engines became more widely and intensively used, and by the middle of the nineteenth century coal had displaced wood as the main fuel. These technologies enabled and expanded mechanized production (powered billows for blast furnaces, displaced waterwheels to boost food and textile mill capacities) and transport (steam ships and rail locomotives). This steady refinement and spread of coal and steam technology through the English economy was facilitated by supportive institutions that emerged from a fraying of the English monarch's authority. The spreading and balancing of political powers in England, including development of the rule of law with some independence from the crown, laid important societal, political and institutional foundations for innovation and entrepreneurship as well as private investment and finance (Acemoglu and Robinson, 2012, pp. 182-212). Markets for commodities also expanded with growing international trade and European colonization of the Americas and parts of Africa and Asia. While it is perhaps by a sequence of happenstances that industrialization through entrepreneurship and private investment began in England, the demonstration effect was soon seen in other countries.

The direction and pace of technological innovation was increasingly shaped by entrepreneurial initiatives, expanding market opportunities, international trade and the diffusion of knowledge within and across countries. Coal and steam technologies soon spread across Europe, where coal resources were accessible and technologies could be adapted to local circumstances - initially Belgium and northern France, and subsequently the Ruhr Valley in Germany (Fernihough and O'Rourke, 2014). The knowledge and technology spread well beyond Europe to the United States and Japan by human travel, while Switzerland industrialized on the back of its significant innovation capabilities, renewable energy resources and imported coal. Coal and steam technologies reached into more economic sectors too, scaling up production of food, leather, textiles and metals (mostly iron) in factories and transport by steam ship and locomotive. In Britain, which was then at the technological frontier, growth in average real per capita incomes rose at an annual average rate of 0.5 per cent from 1700 to 1870, a significant acceleration from the pre-industrial rate.

By the end of this period - the first industrial revolution - the real average per capita income in Britain reached $\$ 3,850 .{ }^{9}$ Those in the United States and Belgium reached $\$ 3,740$ and $\$ 3,370$ in 1870 , respectively, as these countries closed the technological gap with Britain. In France and Germany, they were around $\$ 2,400$ in 1870 . The composition of economic activity changed as well. By 1870 in Britain, industrial production and services (including transport) each accounted for about 35 per cent of total output. Belgium and France also attained industry shares of total output of at least 30 per cent, with Germany just below (Fremdling and Solar, 2010). However, the Netherlands, which 
had gained early prosperity from shipbuilding, trading and productive agriculture, was only a latecomer to the industrial revolution, owing to diminished capacities for innovation and political upheavals from the French Revolution (Mokyr, 2000).

Industrialization in the technologically leading countries and their sustained growth in per capita output were fuelled by a surge in energy use. Average annual per capita energy use in Great Britain rose to about $120 \mathrm{GJ}$ in 1870, up from 30 GJ in England in 1700, a four-fold increase (Warde, 2007, pp. 131-8). At the same time, per capita incomes rose by almost 2.5 times. Taken together, they point to a very high additional energy use to fuel economic growth - a factor of 1.7-at the technological frontier. ${ }^{10}$ This underscores both the societal imperatives of expanding production and consumption possibilities beyond those achieved in the Malthusian epoch, and the inefficiencies of the new technologies in converting energy into useful work and output. In fact, the productivity of energy in terms of real gross domestic product (GDP) per GJ fell in Great Britain to $\$ 32 /$ GJ in 1870 from $\$ 55 /$ GJ in England in 1700, when it was still a largely agricultural society with some coal for heating. There was, however, much technological potential to improve energy productivity.

Coal and steam technologies enabled not only growing industrialization but also increasing urbanization which helped to create a social basis for modern nation states to emerge. Britain and Belgium, along with the Netherlands, had urban population shares in 1870 of 35-40 per cent, while the Western European average reached about 15 per cent. Industrialization and urbanization worked against the feudal political and social order that had prevailed in Western Europe for centuries and facilitated the formation of new social groups-workers, students, professionals and managers (Fukuyama, 2014, pp. 40-51). In anonymous cities, people gained more fluid identities that were no longer necessarily bound to village or family. New identities took new forms, including nationalism, and modern nation states sought to forge national identities in several ways. They included building railroad networks in the nineteenth century that served to link cities, towns and peoples (Fukuyama, 2014, pp. 165-84). These technological, social, political and institutional changes helped lay the foundations for the next wave of private innovation and investment and the second industrial revolution. They also abetted Western imperialism and national rivalries, and the industrialization of human conflict (Morris, 2010, pp. 490-526).

\section{The Second Industrial Revolution: Oil, Electricity and Consumer Societies}

The initial impetus for tapping crude oil was to find an alternative to whale oil for lighting, which was becoming increasingly scarce due to over-hunting, 
much as forest depletion prompted the initial switch to coal from wood in England. Kerosene, which is refined from crude oil by distillation, was a good alternative for oil lamps. While the existence of crude oil was long known from natural oil seeps and ponds, the first wells to tap into underground reservoirs beneath them were drilled in the mid-1800s in Azerbaijan and Pennsylvania. But the development that really spurred on the oil industry was the invention and refinement of internal combustion engines in the 1880s and 1890s in Germany and France. In contrast to steam engines, which rely on external combustion and boilers to produce steam, internal combustion engines burn liquid fossil fuels which are injected together with air into cylinders and burned to drive reciprocating pistons within them. They were more compact and efficient machines than steam engines, and fuels from distilled crude oil were more energy-dense than coal.

As with steam engines, initial applications of internal combustion engines were for stationary purposes, but as their design became more efficient they began to be used for road transport to power automobiles and trucks by the beginning of the twentieth century. While Germany and France saw their early designs take shape, it was in the United States where affordable, mass-produced automobiles gained broad societal use through assembly-line production, modern business organization, consumer finance and marketing pioneered by automobile manufacturers. Automobiles and gasoline rapidly replaced the horse and biomass in the early decades of the twentieth century as the main mode of road travel in the United States, facilitated by significant government investment in paved roads and fuelled by a growing oil industry. While automobiles and gasoline soon offered faster transport at lower cost per mile than horses and biomass, they also became part of a rapidly growing American consumer culture (Gordon, 2016, pp. 62-171). From virtually nil in 1900, US automobile ownership reached 187 per 1000 of population by 1930 , a level not reached in Western Europe and Japan until the 1960s or later (Cain, 2006; Dargay et al., 2007).

The development of motorized road transport occurred in the context of a much broader wave of rapid technological progress, as the interactions among accumulating scientific knowledge, its engineering applications and experienced-based learning intensified. Modern energy and machines transformed many economic activities and sectors at the same time. They included breakthroughs in iron- and steel-making in Britain and Germany that raised quality and lowered costs, allowing wider applications in buildings and bridges and rapid expansion of railroads and shipping. The increased precision of machine tools and standardized measures enabled metal parts to be made to standard shapes and sizes and to close tolerances necessary for complex machines and mass production. This innovation, for example, transformed the manufacturing of transport vehicles - not only automobiles and trucks, but 
also trains, ships and in time airplanes. Paper-making machines made possible the low-cost production of paper and in turn mass communication through printed media. The invention of the telephone in America made instantaneous long-distance voice communication possible over wires, while that of the radio in Britain dispensed with wires for voice transmission.

But perhaps the most important new technology developed in the latter part of the nineteenth century was electricity. While a systematic understanding of electricity had accumulated through the efforts of many scientists since the late eighteenth century, a key breakthrough was the discovery in Britain that magnetism could produce a steady flow of electricity, and this opened the way for producing electric power from a rotating magnetic field. The steam turbine, also developed in Great Britain in the late 1800 s, became the primary device for rotating a magnetic field around a stationary set of conductors (wires wrapped around an iron core) to produce a continuous flow of electricity. These turbines produce rotating motion from steam created at high pressure from a boiler and directed through the turbine blades to rotate them. The main initial use of electric power was lighting for commercial buildings and factories, which substantially improved both lighting quality and fire safety. Electromagnetic motors also expanded substantially the use of electricity to power machines in factories, replacing steam engines and belt drives. The commercialization of electricity generation, distribution, metering and electric lighting and motors was initiated in London and New York, integrating these technologies into electricity systems.

Electricity systems transformed not only commercial building and factories but also households. The connecting of large numbers of buildings and end users to energy networks began in the United States and Western Europe in the early 1900s. Coal and wood had been the main fuels for heating and hot water in houses for centuries, while an opened window provided cooling and ventilation if needed. By the middle of the twentieth century, the transformation of American households was extensive. More than half the population lived in urban areas by 1940 and virtually all urban households had access to electricity, three-quarters to natural gas for heating and hot water, and more than half had central heating (Gordon, 2016, pp. 115-26). Electricity, refrigeration and freezing transformed the production, transportation, retailing and household storage of food. The proliferation of electrical appliances transformed how household activities were undertaken and became the cultural norm of an American home. Western Europe and Japan lagged behind the United States in these developments, owing in part to the dislocations of war, but nevertheless followed similar albeit delayed pathways.

Development of energy networks in the United States and Western Europe to serve households, commercial buildings and factories also marked a change in how energy and energy-using technologies were developed and provided. 
The early inventors and entrepreneurs in electricity integrated the entire value chain from electricity generation, transmission and distribution to customers by creating vertically integrated utilities. These early efforts were focused on major cities-Berlin, Chicago, London and New York-where per capita incomes, concentrations of economic activity and density of potential electricity demand were high. They were also shaped by the interplay between entrepreneurial and political interests in the sanctioning of public utilities. In New York and Chicago, the interests of technology tended to dominate the politics; in London it was the reverse (Hughes, 1983, pp. 461-5). In Berlin before the First World War, there was effective coordination of political and technological power, facilitating growth in both supply and demand necessary for achieving the significant economies of scale and lowering costs for customers. Similar considerations led major electrical equipment manufacturers to supply and standardize electrical appliances and promote the social norm of a modern household and industrial society in advertising to develop demand for both electrical equipment and appliances (Hughes, 1989; Nye, 1990, pp. 259-77).

As these energy, technology, societal and institutional developments transformed many areas of economic activity, the United States and Western Europe saw sharp accelerations in output growth and rising living standards. By 1940, US real per capita income almost tripled to $\$ 10,450$ from its 1870 level, achieving an average annual growth rate of 1.5 per cent. ${ }^{11}$ This rate and extent of sustained improvement in living standards was then without historical precedent. Real per capita incomes also rose in Western Europe, but at a slightly slower average rate of 1.3 per cent, reaching $\$ 9,260$ in Britain in $1940, \$ 7,570$ in Germany and $\$ 6,060$ in France (both in 1939). Per capita incomes in the United States and Western Europe doubled in less than 70 years. The two previous doublings of per capita incomes in Western Europe took about 150 years and 2000 years.

Average per capita energy use in the United States reached about 220 GJ in 1940, up from about $110 \mathrm{GJ}$ in 1870 (excluding food). ${ }^{12}$ While growth in output and living standards accelerated, the energy intensity of economic growth fell at the technological frontier to 0.6 from 1.7 in the first industrial revolution. This reflects the fact that the second wave of technologies for converting energy into useful outputs were much more efficient than those in the first. As the United States took over from Britain at the technological frontier, especially in scaling up and commercializing new energy technologies, GDP per unit of energy in the United States rose to \$48/GJ in 1940 from \$32/GJ in 1870 . These energy and technology advances also scaled up military conflicts between nation states and fuelled energy insecurities in some for want of access to primary energy resources. 


\section{Globalization: Logistics, Aviation and Digitalization}

Globalization - the growing worldwide interconnections among peoples and nations - is perhaps the defining political, economic and social development of the late twentieth century and early twenty-first century (Steger, 2017, pp. 11-17). Energy plays an important physical role in connecting places and peoples, but its indirect impact on globalization has been perhaps as great.

This recent wave of globalization emerged gradually from the ashes of the Second World War. The political response to this catastrophic intensification of human conflict among industrialized nations was the creation of a new liberal world order among nation states supported by several multilateral institutions. This approach to international relations aims to use markets more, and political coercion and military force less, to mediate relationships among nation states, with the multilateral institutions overseeing rules for these markets and providing a forum for cooperation among governments (the United Nations). The key markets in this world order are for international investment and finance, foreign exchange (money) and trade in goods. Their supporting institutions are the World Bank, International Monetary Fund and General Agreement on Tariffs and Trade (subsequently the World Trade Organization). The political ascendance of liberalism in the 1980s in the West and the so-called Washington consensus applied to these markets a heavy dose of market liberalization, which accelerated and deepened globalization to an extent last seen when the first era of globalization peaked in 1914 at the start of the First World War (Rodrik, 2011, pp. 24-44). The political collapse of the Soviet Union, significant economic liberalization in China and market-oriented reforms in India also greatly expanded the scope for these markets and global interconnections. While these political developments supported rapid expansion in trade and capital flows, and catch-up growth in some developing countries, mostly in Asia, they also occasioned a significant widening of income inequality in many advanced industrialized countries (Alvaredo et al., 2018, pp. 40-77).

Energy and energy-using technologies also played an important supporting role in the current wave of globalization. Key innovations lowered costs of maritime shipping significantly and air transport dramatically as the demand for these services rose with rising real incomes around the world and more open markets (Hummels, 2007). In shipping, the innovations related not to ship propulsion but rather to shipping fleet management and containerization-in other words, to the logistics of shipping. The rapid growth in international trade from the 1980s - at a pace much faster than overall economic growthincreased density of trade along major shipping routes and contributed to the emergence of hub ports in Asia, Europe and North America. At the same time, containerization of freight cargoes combined to boost ship utilization and cut freight-handling costs. In aviation, the costs of air passenger fares (per kilo- 
metre travelled) fell precipitously with the introduction and refinement of the jet engine, especially during the 1960s and 1970s. A key breakthrough was the development of highly efficient turbofan engines, which contributed to a significant decline in the relative price of air passenger transport and a ten-fold increase in its volume since $1970 .^{13}$

The other technologies that have enabled vast interconnections among peoples and places are digital technologies for handing information, computing and communicating digital content. The first computers were developed in the United States and United Kingdom for military purposes during the Second World War. The general-purpose mainframe computers developed from them found their initial commercial use in sectors that managed vast amounts of information-banking, insurance and airlines. But it was the development of personal computers in the United States in the 1980s, along with new software that made their use widely accessible and productive, that brought computers out of the back office, onto office desks and into households. At the same time, the US military developed technology for linking computers through wires - intranets - for transmitting electronic data and protocols for linking together networks. These technologies enabled basic digital communication such as email over telephone lines. The vast amount of information communicated through the internet today is made possible by development at the European Organization for Nuclear Research of the World Wide Web, a set of protocols for creating and sharing information across the internet. These innovations, together with fibre optics and advanced mobile telephone networks, transformed how information and media are accessed. They also significantly expand the potential for greater efficiencies in provision of services from energy and materials and alternatives to them.

\section{SPATIAL AND TEMPORAL DIMENSIONS OF ENERGY TRANSFORMATIONS}

Two centuries of developing and expanding modern energy systems in advanced industrialized countries, including recent innovations and developments, provide insights into the spatial and temporal dimensions of these transformations. The new energy resources and technologies of the first industrial revolution emerged initially in England and Northwest Europe, and those of the second in Western Europe and the United States. From these initial markets, where the technologies were conceived, first tested and refined through commercial use, they spread more widely. Over time, they diffused across sectors and countries as they industrialized, a process which continues in developing countries, and with new waves of innovation like information and communication technologies. This process of energy system transformations and industrialization spanned one-half to a full century. For example, 
many of the breakthrough technologies of the first and second industrial revolutions took around half a century to reach market 'maturity' (Perez, 2002, pp. 49-56). Large-scale, capital-intensive infrastructures typically take more than half a century to establish and reach most cities and towns - most firms and households (Grübler et al., 1999). However, at the level of individual technologies, there is much variation in timescales for their development, commercialization and diffusion, including among initial and subsequent markets.

The risks of climate change give rise to a timebound imperative to transform modern energy systems to low-carbon alternatives, and timescales for this change are tight-much tighter than the historical energy revolutions. Looking back, many factors shaped these past changes, including characteristics of the technologies themselves and environments in which they were deployed. Energy-related technologies are very heterogenous, ranging from energy supply and complex industrial processes to relatively simple energy end-use technologies. These various technologies require very different types of innovation and commercialization efforts. They also deploy into widely varying market contexts, ranging from initial to subsequent markets and from competitive to regulated ones. Such differences among energy-related technologies and contexts must be considered when assessing the temporal and spatial dimensions of transforming energy systems to low-carbon technologies, and policies to promote them. Moreover, inferences from past changes cannot simply be extrapolated into the future because of the changing contexts for energy-related technology developments.

For example, some capacities for energy-related innovations have potentially strengthened over time. Scientific investigation and experience-based learning accumulate knowledge over time, including better methodologies for research and experience-based learning. There is also an expansion of scientific and engineering skills through growing investments in education. But better ideas appear to be getting harder to find, needing progressively more intensive research efforts to produce over time, both within and across sectors and technologies (Bloom et al., 2019). Despite potentially diminishing returns to research inputs, such R\&D (research and development) efforts advanced many low-carbon technologies in recent decades, and some are now deploying commercially in markets (see Chapters 3 and 4). Encouragingly, low-carbon technology concepts that could serve many-but not necessarily all — current energy, energy-service and material demands exist at least at a pre-commercial stage (Chapter 3). Indeed, some technologies have existed for a century or more, such as electrolysers and fuel cells for production and use of hydrogen. But their development and deployment remain limited, serving only commercial niches. More such concepts are needed to respond fully to the challenges of transforming current energy systems to low-carbon technologies, enable 
testing of alternative low-carbon technologies in initial markets and allow for market selection of the ones best suited to customer needs.

Other contexts for energy-related innovations and change have arguably become more challenging over time. Energy 'system' starting points for the first two industrial revolutions were decentralized and small-scale, and based on the capture and use of traditional energy resources that were inherently local. For example, low-energy-density fuels like feed, wood and dung, and conversion technologies like draught animals, have high transport costs relative to their value in providing energy and energy services. Deploying new technologies into these market contexts offered many early adopters clear net expected economic benefits. In contrast, starting points for transformation to low-carbon energy technologies are highly complex modern energy systems which emerged because of significant complementarities among technologies and scale economies. Some arise from network effects, as with railroads, paved public roads, and transmission and distribution networks for electric power and natural gas. Others are external to individual firms and households, like transport vehicles having the same drivetrain technologies and using standardized transport fuels. These systems of interrelated technologies, infrastructures, institutions and societal norms took one-half to one century to mature. But once established, they can lock-in some incumbent technologies by raising the costs to individual firms and households of switching to alternatives (Arthur, 1989; Unruh, 2000; Seto et al., 2016). Such lock-in effects are inherent to energy systems of interdependent technologies and infrastructures, which create high costs for transforming systems, at least in the early stages of adopting alternative low-carbon technologies. However, some low-carbon fuels and technologies afford 'drop in' or 'bolt-on' alternatives, such as sustainable biofuels and carbon dioxide capture, use and storage, which largely avoid such switching costs.

While recognizing that contexts for transforming current energy systems differ from those of past energy innovations, the experiences of the historic transformations and more recent technological innovations highlight several temporal and spatial characteristics of change. This process of change can be portrayed as consisting of four stylized stages: (1) development of new technology prototypes, primarily through investments in R\&D; (2) demonstration of successful new prototypes at a commercial scale; (3) their early deployment and commercialization in initial markets where they are refined and adapted to customer needs; and (4) widespread diffusion across markets, sectors and countries. To give a sense of timescales for energy-related technologies, the median times for a sample of recent electricity-generation technologies to traverse their stages of research, development and demonstration (stages 1 and 2) and market deployment and commercialization in their initial market (stage 3 ) are 24 years and 18 years, respectively (Figure 1.1; Gross et al., 2018). 
Timescales for these two stages for energy end-use technologies and consumer products are shorter: 12 years and 15 years, respectively.

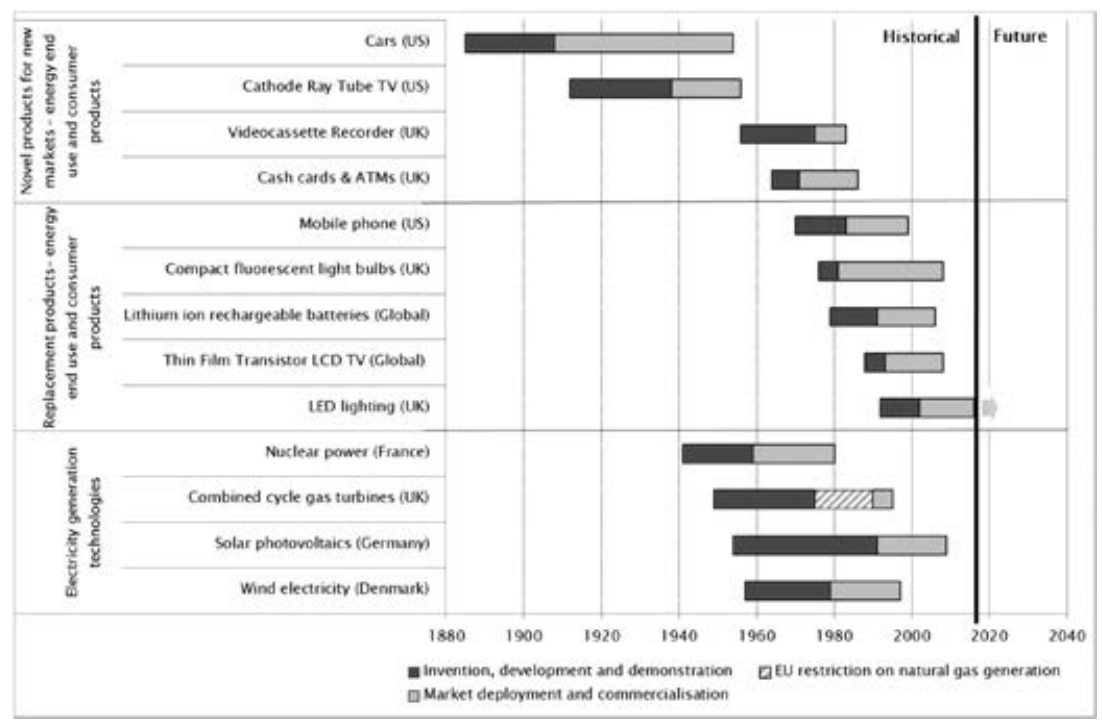

Notes: The figure groups innovation timescales by technology characteristics and category: novel energy end use and consumer products (new products with entirely new markets); replacement energy end use and consumer products (new technologies which replace but perform a similar function to an existing product); and electricity-generation technologies. Invention, development and demonstration are innovation activities prior to commercial availability. Market deployment and commercialization span the period from commercial introduction to a 20 per cent share of the potential market.

Source: Reprinted from R. Gross et al. (2018), How long does innovation and commercialisation in the energy sector take? Historical case studies of the timescales from innovation to widespread commercialisation in energy supply and end use technology, Energy Policy, 123, 682-99 (CC BY 4.0). https://doi.org/10.1016/j.enpol.2018.08.061.

\section{Figure 1.1 Energy technology innovations and initial market deployment} timelines

The least well researched and understood product life-cycle stage is 'market deployment and commercialization', but it is one that is likely to play a key role in transforming energy systems, so it is important to take a closer look at available evidence. In studies using a range of definitions and measures for this product life-cycle stage, a consistent finding is that new technologies which substitute easily for existing ones achieve market commercialization more quickly than novel technologies in initial markets (Grübler et al., 1999; Bento and Wilson, 2016; Sovacool, 2016; Bento et al., 2018). Technologies that are long-lived and components of interconnected technologies and infrastructures 
tend to take the longest to diffuse, but notable exceptions are jet engines and nuclear power, which government interventions helped to accelerate (motivated in part by military and energy security aims) (Grübler et al., 1999; Bento et al., 2018). Government interventions such as public procurement can thus accelerate the pace of commercialization of new technologies. There is also some evidence that the market deployment and commercial stage for new technologies deploying in subsequent markets advanced more quickly than in initial markets, although the size of the effect is not large (Wilson and Grübler, 2011; Bento et al., 2018). This finding points to some potential knowledge spillovers from initial to subsequent markets and benefits from investments in absorptive capacities for new technologies in subsequent markets, such as developing countries.

Drawing together available evidence on the stages of innovation and new technology diffusion highlights several stylized facts about their overall pace from invention to market maturity. Those energy-related technologies associated with a relatively slow overall pace in reaching product maturity have several common technology characteristics or deployment conditions (Grübler et al., 2016). They are: (1) multiple changes in technologies, infrastructures, social norms and institutions and large-scale investments needs; (2) extensive development and early-stage deployment of new technologies that must be tested in and adapted to market contexts; (3) low immediate individual adaptation benefits for firms and households, and complex coordination issues between centralized (regulatory) and decentralized (firm and household) decisions. More rapid transformations tend to have converse characteristics of slow transformations (Sovacool, 2016). They involve: (1) new technologies that easily substitute for incumbent ones, (2) alternative technologies that were previously used in other markets and can be readily adapted to new markets, and (3) new technologies that offer significant and multiple benefits to individual adopters. Potential low-carbon technologies and their deployment environments feature a range of such characteristics. Their eventual mix would likely reflect in part societal choices on timescales for change, with tighter timetables directing low-carbon technology development and deployment towards those that have characteristics associated with more rapid energy transformations.

\section{CONCLUSION}

Sparked by an industrial enlightenment and propelled by successive waves of energy-related innovations, human capabilities to capture energy on a vast scale and use it well have soared, transforming societies - both positively and negatively. Modern energy systems lifted standards to unprecedented heights in advanced industrial countries, and they make vital contributions to growing prosperity in developing countries. Current energy systems and fossil fuels are 
deeply woven through the fabric of modern economic activities and household lives. But mounting cumulative emissions of carbon dioxide from fossil fuels and other greenhouse gas emissions are confronting societies with the risks of climate change. To transform current energy systems, most firms and households must invest in low-carbon alternatives, but such changes raise challenging economic, social and political issues. They include the vast scale of the change in terms of new investments, lock-in of some incumbent technologies in investment decisions of individual firms and households, and distributional impacts within and across societies. Incumbent technologies also benefit from un-costed carbon dioxide emissions, a market failure that must be corrected. Markets have an important role in enabling these changes to take place, as do government policies and energy-reform strategies (Parts II and III).

Historic energy transformations and more recent technology developments provide useful insights into potential market-based dynamics of developing, commercializing and widely diffusing new low-carbon technologies on a global scale. At a systems level, energy transformations are slow-moving, spanning a century or more. Within systems, some changes are indeed slow, like those to infrastructures and energy networks, which consist primarily of long-lived and interdependent technologies. Other changes are relatively quick, like light-emitting diode technology that substitutes easily for compact fluorescent and incandescent lightbulbs. Most potential changes to low-carbon energy technologies fall somewhere in-between these two examples. Moreover, tighter timetables for transforming energy would likely tilt technologies choices towards those with characteristics that facilitate their more rapid deployment and widespread diffusion, at least in the first wave. It is thus important to take a close look at current energy systems and the useful services and materials they provide, along with foreseeable alternative low-carbon technologies that could maintain and grow their provision in advanced industrialized and developing countries (Chapters 2 and 3).

\section{NOTES}

1. The terms 'advanced industrialized' and 'developing' countries draw broad distinctions among countries, their level of technological development, industrialization and material living standards. This distinction is similar to- but not always precisely the same as - the International Energy Agency (IEA) country classification system for analysis of global energy use of Organisation for Economic Co-operation and Development (OECD) member countries and non-OECD countries. It is also similar to the 1997 Kyoto Protocol Annex II Parties (then OECD member countries), which assumed obligations to provide financial resources to developing countries for climate change mitigation and adaptation purposes.

2. Adapted from the definition of energy in the Oxford English Dictionaries. Retrieved from https://en.oxforddictionaries.com/definition/energy. 
3. The International System of Units (SI), Laboratoire National de Métrologie et d'Essais. Retrieved from www.french-metrology.com/en/si/units-measurement .asp.

4. FAOStat. Retrieved from http://fenixservices.fao.org/faostat/static/documents/ CountryProfile/pdf/syb_5000.pdf.

5. IEA Data \& Statistics and OECD Data. Retrieved from www.iea.org/data -and-statistics/data-tables and https://data.oecd.org, respectively. Figures exclude non-energy use of fossil-fuel resources for production of chemicals and other materials.

6. This section draws on extensive research on the agricultural revolution, human settlement and societal development around the world from several disciplinesarchaeology, geography, history and energy. See, for example, Diamond (1997), Kander et al. (2013), Harari (2015), Scott (2017) and Smil (2017).

7. Historical national GDP data are from the Maddison Project Database Version 2018, University of Groningen. Retrieved from www.rug.nl/ggdc/historicalde velopment/maddison/releases/maddison-project-database-2018. See Bolt et al. (2018) on the database methodology.

8. This section and the next one draw on extensive research on the first and second industrial revolutions from several disciplines - history, economics and energy. See, for example, Mokyr (2002, 2009), R.C. Allen (2009), Kander et al. (2013), Jacob (2014), Gordon (2016) and Smil (2017).

9. Maddison Project Database Version 2018, op. cit.

10. This factor is the energy intensity of real GDP growth; that is, the per cent change in energy use divided by the per cent change in real GDP.

11. Maddison Project Database Version 2018, op. cit.

12. US energy figures are linear interpolations of data from Smil (2017), p. 458.

13. See Smil (2017, p. 333) on the efficiency of turbofan jet engines. The air passenger kilometres figures are World Bank statistics retrieved from https://data.worldbank .org/indicator/IS.AIR.PSGR. 